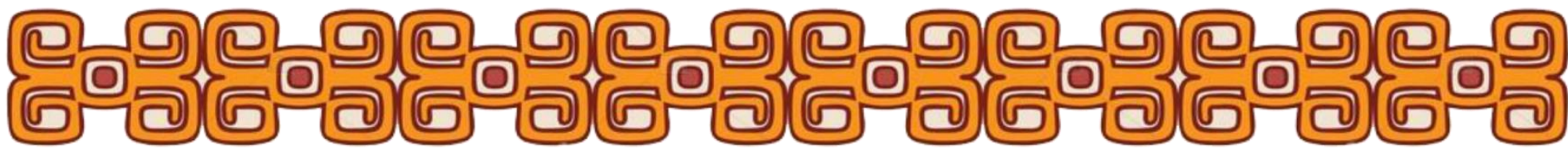

\title{
PARADIGMAS DO ACESSO AO CONHECIMENTO PARA A INCLUSÃO DA PESSOA COM DEFICIÊNCIA COM BASE NOS ESCRITOS DE NORBERT ELIAS
}

Tássia Patricia Silva do Nascimento

\begin{abstract}
RESUMO
O texto busca aproximar algumas ideias apresentadas pelos escritos de Norbert Elias à proposta de inclusão escolar da pessoa com deficiência. Assim, considera tais pessoas, como marginalizados da escola comum e elucida a estigmatização desses indivíduos no contexto da educação inclusiva. Trata-se de um artigo teórico que problematiza a figuração escolar no processo de inclusão dos alunos com deficiência.
\end{abstract}

\section{PALAVRAS-CHAVE}

Pessoa com Deficiência; Inclusão, Educação.

\section{INTRODUÇÃO}

Esse artigo procura ter como fundamentação a questão da Figuração que é um conceito central na elaboração teórica de Norbert Elias que, utilizando-se desse conceito, coloca as relações como ponto de partida na investigação sociológica e acentua a ideia de que os indivíduos e grupos humanos só podem existir em figurações ou em inter-relações (ELIAS, 1994).

Conforme nos esclarece o autor, uma figuração pode ser formada por um número restrito de pessoas, como um casal ou um grupo de alunos, ou até mesmo por milhões delas, como uma nação, assim como pode se referir tanto a relações harmônicas, quanto a relações hostis e tensas entre as pessoas e os grupos que as formam.

Dessa forma, Segundo Elias (2001), os seres humanos singulares se transformam nas figurações ao mesmo tempo em que transformam as figurações que eles constituem. Desse modo, ações e autores, indivíduo e sociedade são indissociáveis.

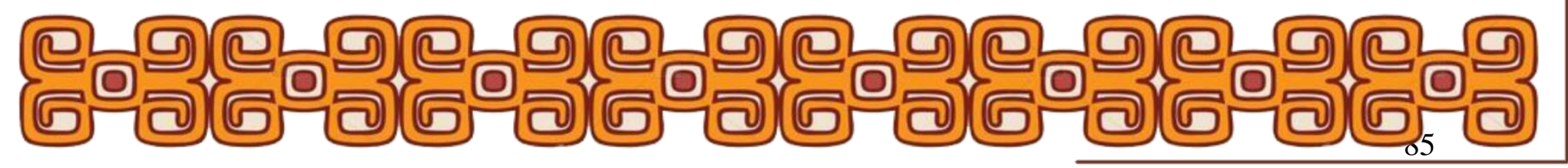




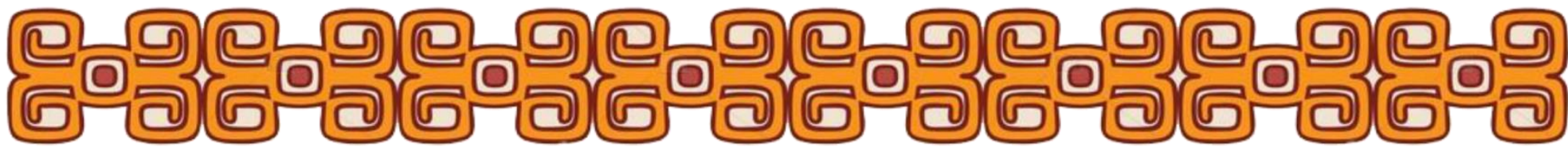

Em outras palavras, individualização e socialização são diferentes denominações que se referem a um mesmo processo. Dessa maneira, surge à questão da pessoa com deficiência, tema abordado nesse artigo. Por meio do conceito de figuração, Elias acena para a incerteza e para imprevisibilidade das relações estabelecidas entre indivíduos e/ou grupos humanos, afinal essas relações são, necessariamente, relações de poder.

Podemos então destacar outra elaboração elisiana que contribuiu nas análises e discussões que desenvolveremos em nossa investigação: o equilíbrio (ou a balança) de poder nas relações humanas. Diante das inúmeras e inesperadas circunstâncias sociais vividas, Elias considera o poder como elemento constituinte de qualquer relação. Segundo o autor, "[...] Desde que nasce, a criança tem poder sobre os pais, e não só os pais sobre a criança". Da mesma forma, "[...] O senhor tem poder sobre o escravo, mas o escravo também tem poder sobre o seu senhor" (ELIAS, 2005, p. 81), ainda que essas oportunidades de poder sejam distribuídas/equilibradas muito desigualmente. Com essa perspectiva que vamos adentrar nas configurações do artigo em questão em se tratando dos desafios a educação da pessoa com deficiência.

\section{TRAGETÓRIA HISTÓRICA DA PESSOA COM DEFICIÊNCIA}

De acordo com a Política Nacional para Integração da Pessoa Portadora de Deficiência (1993. p. 12) "deficiência é toda perda ou anormalidade de uma estrutura ou função psicológica, fisiológica ou anatômica que gere incapacidade para o desempenho de atividades dentro do padrão considerado normal para o ser humano".

A deficiência assumiu vários significados ao longo da história: pessoas inúteis, incapacitados, defeituosos, pessoas portadoras de deficiência, pessoas com necessidades especiais, etc.

Nesse sentido, a trajetória da Pessoa com Deficiência, vem se mostrando de modo ainda tímido, e começou apesar de tudo em países da Europa e América do Norte, foram assim, identificados quatro estágios no desenvolvimento do atendimento (KIRK e GALLAGHER, 1979; MENDES, 1995; SASSAKI, 1997).

Inicialmente é evidenciada uma primeira fase, marcada pela negligência, na era précristã, em que havia uma ausência total de atendimento. Os deficientes eram abandonados,

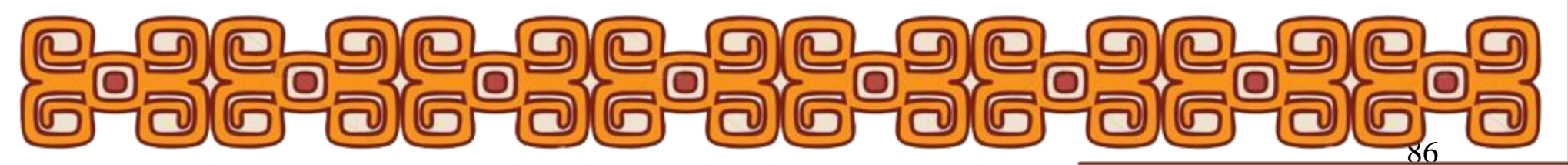




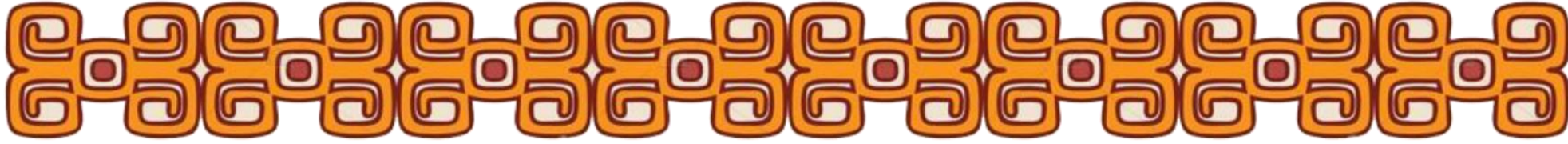

perseguidos e eliminados devido às suas condições atípicas, e a sociedade legitimava essas ações como sendo normais. Na era cristã, segundo Pessotti (1984), o tratamento variava segundo as concepções de caridade ou castigo predominantes na comunidade em que o deficiente estava inserido.

Desse modo, Elias (2000) relata que a sociedade ao se dividir em grupos sociais, fator empírico da época, alguns desses grupos se consideram mais poderosos e melhores que os outros grupos, grupos esses inferiores, identificados como marginalizados da sociedade. Obtendo como instrumento de poder a coesão interna e o controle comunitário. Neste sentido é possível observar e comparar a sociodinâmica da estigmatização nesse período da antiguidade onde o poder gerado pela coesão dos grupos considerados "perfeitos" e pelo controle que possuíam entre seus grupos, condenava os "não perfeitos" atribuindo a eles maus tratos e a exclusão da sociedade.

Num outro estágio, nos séculos 18 e meados do século 19, encontra-se a fase de institucionalização, em que os indivíduos que apresentavam deficiência eram segregados e protegidos em instituições residenciais. O terceiro estágio é marcado, já no final do século 19 e meados do século 20, pelo desenvolvimento de escolas e/ou classes especiais em escolas públicas, visando oferecer à pessoa deficiente uma educação à parte. No quarto estágio, no final do século 20 , por volta da década de 70 , observa-se um movimento de integração social dos indivíduos que apresentavam deficiência, cujo objetivo era integrá-los em ambientes escolares, o mais próximo possível daqueles oferecidos à pessoa normal.

Podemos dizer que a fase de integração fundamentava-se no fato de que a criança deveria ser educada até o limite de sua capacidade. De acordo com Mendes (1995), a defesa das possibilidades ilimitadas do indivíduo e a crença de que a educação poderia fazer uma diferença significativa no desenvolvimento e na vida das pessoas aparecem no movimento filosófico posterior à Revolução Francesa. Desse momento em diante o conceito de educabilidade do potencial do ser humano passou a ser aplicado também à educação das pessoas que apresentavam deficiência mental.

Chegamos finalmente à fase da inclusão, onde estamos amparados legalmente ate hoje, nessa fase todo ou qualquer individuo se vê dentro de um contexto onde as particularidades são deixadas aquém, e dentro das modalidades da sala de aula estamos todos inclusos e fortalecendo nossas potencialidades, pessoas com deficiência ou não.

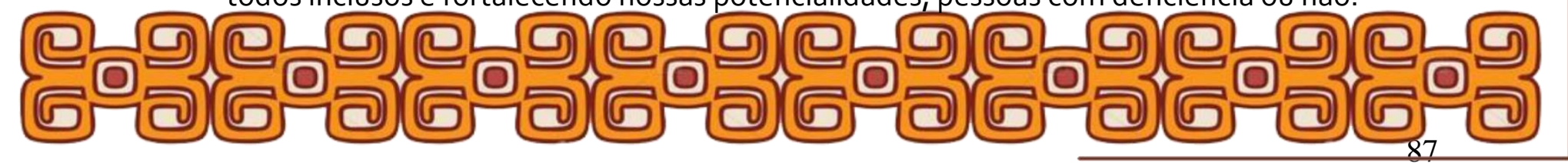




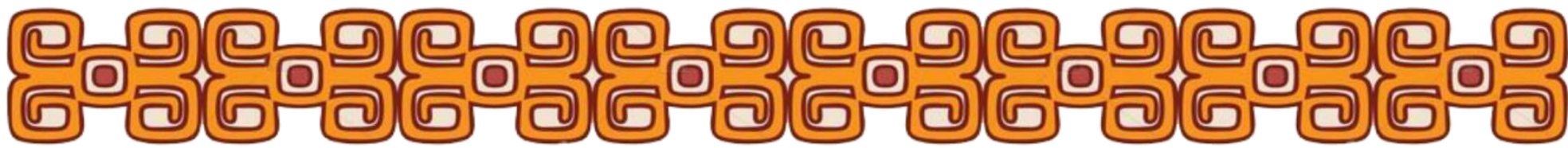

Todas as pessoas com necessidades especiais devem ser inseridas em classes comuns, sendo que os ambientes físicos e os procedimentos educativos é que devem ser adaptados aos alunos, conforme suas necessidades e especificidades. Entende-se por inclusão de acordo com Sassaki (2010)., "é um processo que contribui para um novo tipo de sociedade através de transformações, nos ambientes físicos (...) e na mentalidade de todas as pessoas".

\section{O ACESSO À ESCOLA DA PESSOA COM DEFICIÊNCIA}

Quando dirigimos o nosso olhar para a história da Educação Especial no Brasil, verificamos que a evolução do atendimento educacional especial irá ocorrer com características diferentes daquelas observadas nos países europeus e norte-americanos. Os quatro estágios identificados em tais países não parecem estar estampados na realidade brasileira (MENDES, 1995; DECHICHI, 2001).

A fase da negligência ou omissão, que pode ser observada em outros países até o século 17, no Brasil pode ser estendida até o início da década de 50. Segundo Mendes (1995), durante esse tempo, observamos que a produção teórica referente à deficiência esteve restrita aos meios acadêmicos, com escassas ofertas de atendimento educacional para as Pessoas com Deficiência.

Entre os séculos 18 e 19 podemos identificar a fase da institucionalização em outros países do mundo, marcada pela concepção organicista, que tinha como pressuposto a ideia de a deficiência mental ser hereditária com evidências de degenerescência da espécie. Assim a segregação era considerada a melhor forma para combater a ameaça representada por essa população. Nesta mesma ocasião, no nosso país, não existia nenhum interesse pela educação das pessoas consideradas idiotas e imbecis, persistindo, deste modo, a era da negligência (MENDES, 1995; DECHICHI, 2001).

A história da Educação Especial no Brasil tem como marcos fundamentais a criação do "Instituto dos Meninos Cegos" (hoje "Instituto Benjamin Constant") em 1854, e do "Instituto dos Surdos-Mudos" (hoje, "Instituto Nacional de Educação de Surdos - INES") em 1857, ambos na cidade do Rio de Janeiro, por iniciativa do governo Imperial (JANNUZZI,1992; BUENO,1993; MAZZOTTA,1996).

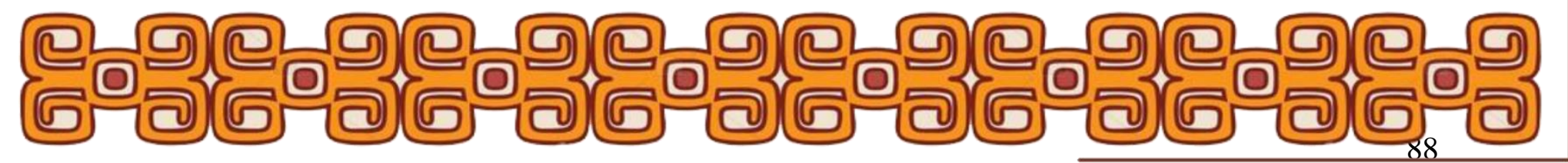




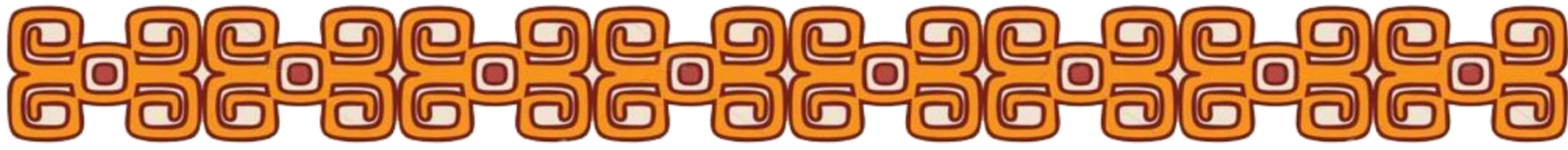

A fundação desses dois Institutos representou uma grande conquista para o atendimento dos indivíduos deficientes, abrindo espaço para a conscientização e a discussão sobre a sua educação. No entanto, não deixou de "se constituir em uma medida precária em termos nacionais, pois em 1872, com uma população de 15.848 cegos e 11.595 surdos, no país eram atendidos apenas 35 cegos e 17 surdos" (MAZZOTTA, 1996, p.29), nestas instituições. Assim, a Educação Especial se caracterizou por ações isoladas e o atendimento se referiu mais às deficiências visuais, auditivas e, em menor quantidade, às deficiências físicas.

Atualmente temos a Lei de Diretrizes e Bases da Educação Nacional em seu Capítulo V - Da Educação Especial, em seu artigo 58, "entende-se por educação especial, para os efeitos desta Lei, a modalidade de educação escolar, oferecida preferencialmente na rede regular de ensino, para educandos portadores de necessidades especiais". No qual dá parâmetros legais de otimização de uma educação mais igualitária para todos os indivíduos.

A Política Nacional da Educação Especial, na Perspectiva da Educação Inclusiva de 2008, estabeleceu que a escolarização do aluno com deficiência deve ocorrer nas classes comuns das escolas regulares, sendo que, quando necessário, este aluno deverá ter à disposição atendimento educacional especializado, que deverá ser ofertado no contraturno, preferencialmente, no espaço denominado salas de recursos multifuncionais.

Tem-se, assim, numa conexão elisiana, uma figuração social em que os alunos com deficiência (outsiders) passam a ocupar a mesma escola ("Winston Parva") que os alunos sem deficiência (estabelecidos), produzindo uma disputa de forças entre os diferentes agentes no tabuleiro escolar (alunos com e sem deficiência, professores do ensino comum e do ensino especializado, pais, gestores, funcionários, etc), a partir de parâmetros de normalidade e da atribuição de prestígio aos grupos que observam as regras e as restrições estabelecidas.

\section{CONTRIBUIÇÕES DE NORBERT ELIAS SOBRE EDUCAÇÃO ESPECIAL, NUMA PERSPECTIVA INCLUSIVA}

Para começar a discussão "Os estabelecidos e os Outsiders", de Norbert Elias (2000), mostra como figuração, uma pequena unidade social como foco da investigação, explora as

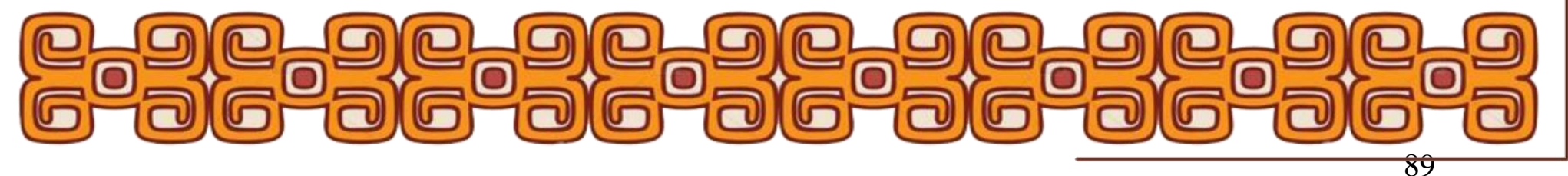




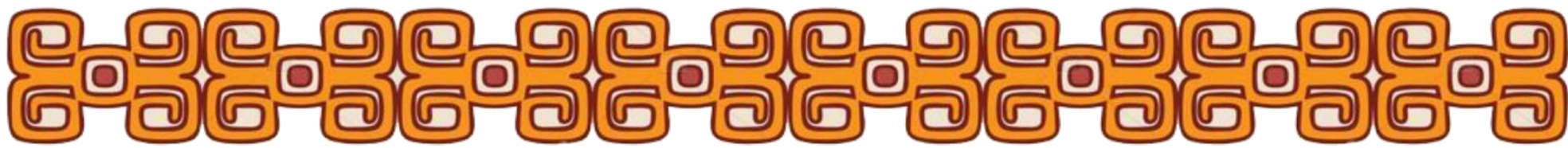

minúcias do que chama "a sociodinâmica da estigmatização", adotando um olhar microscópico para construir um modelo explicativo de uma figuração universal.

Assim, descreve uma comunidade da periferia urbana, na Inglaterra, Winston Parva (nome fictício), onde passam a conviver dois grupos distintos: os que estavam alocados há muito tempo e o que chega posteriormente, e é estigmatizado como sendo composto por pessoas de menos valor.

A possibilidade de um grupo afixar em outro um rótulo de inferioridade humana e fazêlo prevalecer era função de uma figuração específica que os dois grupos formavam entre si. Segundo o Doutor Gláucio Campos Gomes de Matos em sua obra Ethos e Figurações na Hinterlândia Amazônica (2015, p. 98) "O conceito de figuração ajuda a compreender o abismo que põe o indivíduo de um lado e a sociedade de outro. Rompe com a ideia de que a sociedade pudesse existir independente de indivíduos".

É essa justamente a característica distintiva das análises de Norbert Elias, no tocante ao problema da exclusão: as relações interdependentes estabelecidas entre os indivíduos dos diferentes grupos (ou sociedades) definem diferentes configurações (quadros) sociais. Tais relações são entendidas como relações de poder, não só no sentido de detenção dos meios de produção (ou poder econômico), mas, sobretudo como diferenças no grau de organização dos seres humanos implicados.

Entre muitas contribuições de Elias (1994) destacamos a relação entre indivíduo e sociedade, que é conduzida a pensar em termos de relações e funções ao considerar que o que liga as pessoas é uma rede de funções interdependentes, com uma dinâmica própria. Destaca-se principalmente em Elias e Scotson (2000) os conceitos de: figuração, interdependência, equilíbrio de poder e relação entre estabelecidos e outsiders.

A partir das contribuições de Norbert Elias (2000) afirmamos que existe uma sociogênese da educação especial no Brasil. Ocorreram mudanças nas políticas de educação especial no que se referem às abordagens teóricas, conceituação da população a ser atendida, definição da educação especial, lócus do atendimento, serviços e apoios e formação, atribuições do professor de educação especial.

Dessa forma, Elias e Scotson (2000), a partir do conceito "balança de poder", contribuem para o entendimento frente à mudança de um projeto hegemônico da educação. Sendo assim, muitas configurações ocorreram à medida que as correlações de

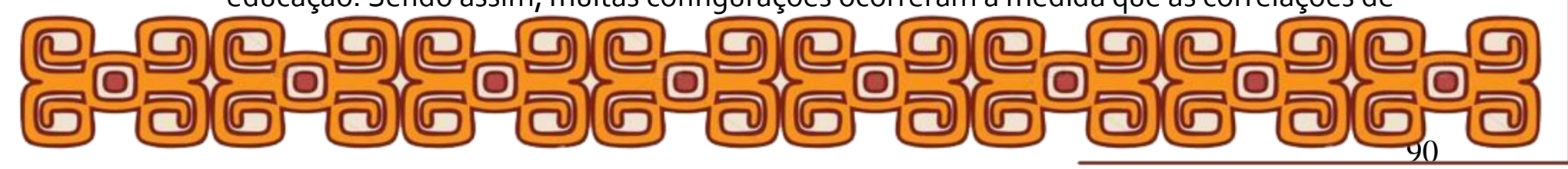




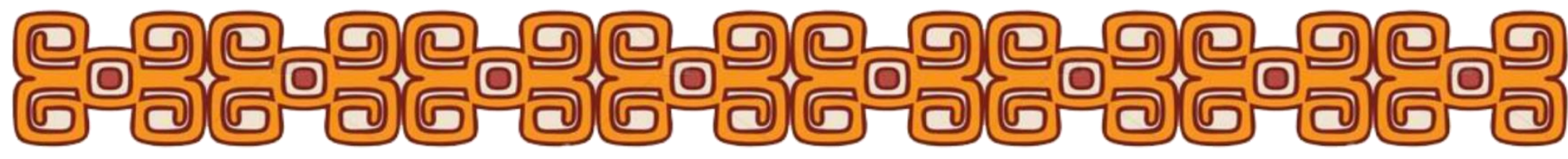

força aconteceram, nas lacunas desse projeto mediante circulação de poder. Chegamos a atual configuração da educação especial enquanto uma modalidade de ensino e podemos refletir com subsidio em Elias e Scotson:

As tensões de grupo inerentes a essa forma de relação podem manter-se latentes (o que costuma acontecer quando os diferenciais de poder são muito grandes) ou aparecer abertamente, sobre a forma de conflitos contínuos (o que costuma acontecer quando a relação de poder se altera em favor dos outsiders). (ELIAS E SCOTSON, 2000, p. 32).

Pensando no papel da educação especial, refletimos sobre o papel do Estado no contexto em dar legalidade e garantir os direitos preconizados para os indivíduos. Nessa perspectiva destacamos a contribuição de Elias (2001) sobre a formação do Estado:

[...] o Estado tem uma função dupla muito peculiar que, à primeira vista, parece contraditória. Por um lado, ele elimina as diferenças entre as pessoas. Nos registros e órgãos estatais, o indivíduo é basicamente despojado de sua personalidade característica. Ele é um nome ligado a um número, um contribuinte ou, conforme o caso, uma pessoa em busca de ajuda e proteção, que as autoridades estatais podem conceder ou recusar. Mas, embora o aparelho de Estado assim introduza o indivíduo numa rede de normas que é basicamente idêntica para todos os cidadãos, a moderna organização estatal não se relaciona com as pessoas como irmãs ou tios, como membros de um grupo familiar ou de uma das outras formas prénacionais de integração, e sim como as pessoas como indivíduos. (ELIAS, 2001, p.149)

Com isso, Elias (2001) nos leva a refletir que existe uma troca intensa de mediação cultural acerca da relação indivíduo e sociedade, que ocorre de modo simultâneo, na qual se deve dar a devida importância ao trabalho colaborativo para as escolas, pois possibilita ao professor, com a sua experiência, colaborar com as resoluções de problemas mais sérios de aprendizagem.

Ao se trabalhar de forma coletiva, Elias (2001) reflete acerca da relação indivíduo e sociedade. Elias destaca que são ideias ilusórias, segundo ele, os conceitos de indivíduo, no qual "se refere a aspectos humanos que existem fora das relações de homens entre si, fora da sociedade" e, por sua vez, sociedade, quando "se refere a algo que existe fora dos 


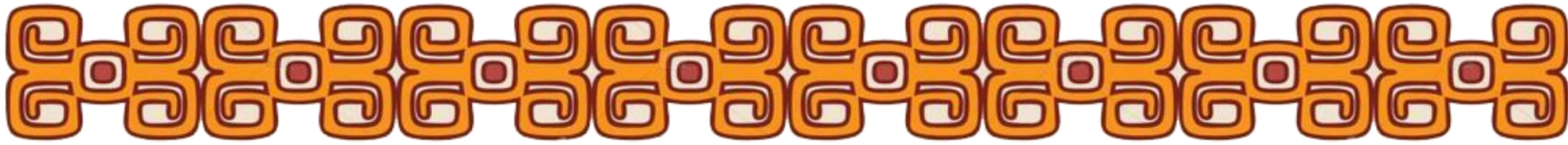

torna interdependente. Afirma, ainda, que o indivíduo é situado a partir de relações tensionais, interdependentes e imprevisíveis articuladas na esfera social, histórica e psíquica, uma vez que são indissociavelmente complementares e tomadas como objeto único das ciências humanas.

\section{REFERÊNCIAS}

ARROYO, M. G. Ofício de Mestre: imagens e auto-imagens. Petrópolis: Vozes, 1998.

BRASIL. Política Nacional para Integração da Pessoa Portadora de Deficiência. Decreto No. 914, de o6 de Setembro de 1993.

DECHICHI, C. Transformando o ambiente da sala de aula em um contexto promotor do desenvolvimento do aluno deficiente mental. Tese de Doutorado. Pontifícia Universidade Católica de São Paulo, 2001.

JANNUZZI, G. A luta pela educação do deficiente mental no Brasil. Campinas/SP: Editores Associados, 1992.

KIRK, S. A; GALLAGHER, J. J. Education exceptional children. Boston: Houghton Miffin Company, 1979 .

ELIAS, Norbert. A sociedade dos indivíduos. Rio de Janeiro: Jorge Zahar Editor, 1994.

ELIAS, N.; SCOTSON, J. Os estabelecidos e os outsiders: sociologia das relações de poder a partir de uma pequena comunidade. Tradução: Vera Ribeiro. Rio de Janeiro: Jorge Zahar, 2000.

ELIAS, Norbert . Investigação sobre a sociologia da realeza e da aristocracia de corte. Rio de Janeiro: Zahar, 2001.

ELIAS, Norbert . Introdução à sociologia. Lisboa: Edições 70, 2005.

MATOS, G. C. G. Ethos e figurações na hinterlândia amazônica. Manaus: Valer/Fapeam, 2015 .

MAZZOTTA, M. J. S. Educação especial no Brasil: história e políticas públicas. São Paulo: Cortez, 1996.

MENDES, E. G. Deficiência mental: a construção científica de um conceito e a realidade educacional. Tese de Doutorado. Universidade de São Paulo. São Paulo, 1995.

PESSOTTI, I. Deficiência mental: da superstição à ciência. São Paulo: T. A. Queiroz: Editora

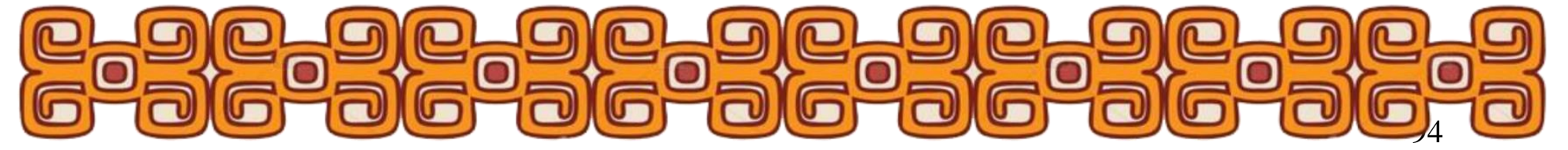




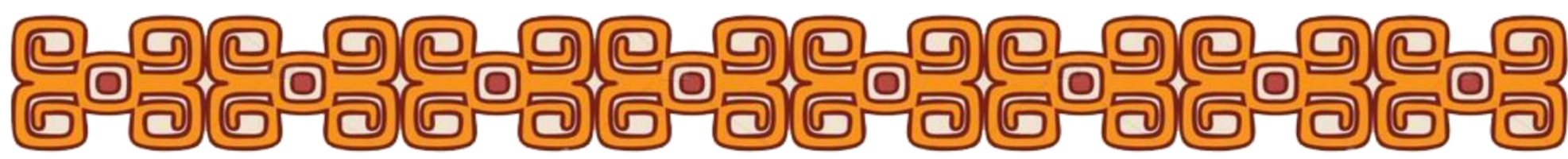

da Universidade de São Paulo, 1984.

SASSAKI, R. K. Inclusão: construindo uma sociedade para todos. Rio de janeiro: WVA, 1997. SASSAKI, Romeu Kazumi. Inclusão: construindo uma sociedade para todos. 8a ed. Rio de Janeiro: WVA, 2010.

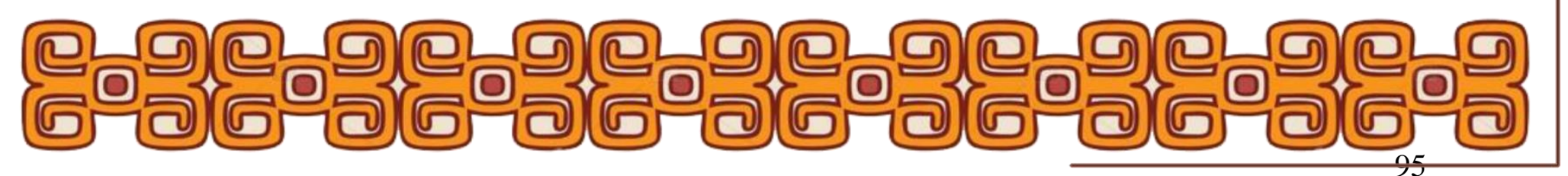

